\title{
Evaluación de la seroconversión como respuesta a la vacunación antirrábica en perros en el departamento del Valle del Cauca, Colombia, 2009
}

\author{
Andrés Páez ${ }^{1,2}$, Constanza Hernández ${ }^{3}$, Humberto Escobar ${ }^{4}$, John Jairo Zapata ${ }^{3}$, \\ Jairo Méndez ${ }^{1}$, Gloria Rey-Benito ${ }^{1,5}$ \\ 1 Laboratorio de Virología, Instituto Nacional de Salud, Bogotá, D.C., Colombia \\ 2 Departamento de Ciencias Básicas, Universidad de La Salle, Bogotá, D.C., Colombia \\ 3 Unidad Ejecutora de Saneamiento del Valle del Cauca, Cali, Colombia \\ 4 Secretaría de Salud Departamental del Valle del Cauca, Cali, Colombia \\ 5 Subdirección Red Nacional de Laboratorios, Instituto Nacional de Salud, Bogotá, D.C., Colombia \\ Instituciones donde se realizó el estudio: \\ Unidad Ejecutora de Saneamiento del Valle, Cali, Colombia \\ Instituto Nacional de Salud, Bogotá, D.C., Colombia
}

Introducción. El departamento del Valle del Cauca ha estado libre de rabia canina por más de 20 años, aunque persisten focos de rabia silvestre que amenazan a humanos y sus mascotas; por ello, como medida preventiva. se realizan anualmente campañas de vacunación antirrábica canina.

Objetivos. Medir el impacto de la vacunación en términos de seroconversión de anticuerpos neutralizadores y de porcentaje de perros con respuesta inmunitaria humoral adecuada, relacionando variables propias de estos animales y de las condiciones de vacunación. Discutir el significado epidemiológico de los resultados y sus implicaciones en salud pública.

Materiales y métodos. Se obtuvo suero e información de 569 perros vacunados en los 42 municipios de Valle del Cauca. La inmunidad humoral se investigó por ELISA cuantitativa. La información se analizó con el programa Epi-Info 6.0.

Resultados. El 9,1\% de los perros de la muestra fueron seronegativos y el 25,1\% no evidenciaron respuesta inmunitaria humoral adecuada a la vacunación. La concentración de anticuerpos disminuyó gradualmente desde la aplicación de la vacuna, y estuvo asociada a edad y calidad de las vacunas, aunque no estuvo asociada a sexo ni a raza.

Conclusiones. Con el fin de aumentar los porcentajes de perros seropositivos y con respuesta inmunitaria humoral adecuada, se hacen las siguientes recomendaciones: 1) utilizar vacunas antirrábicas viables; 2) aplicar dos dosis de vacuna durante los primeros seis meses de vida de los cachorros; 3) aplicar refuerzos de vacuna, por lo menos, una vez al año; 4) que las autoridades vigilen las actividades y los procesos programáticos relacionados con la vacunación antirrábica por particulares.

Palabras clave: vacunas antirrábicas, virus de la rabia, Lyssavirus, zoonosis, vigilancia epidemiológica, inmunidad, Colombia.

Evaluation of the seroconversion as a response to rabies vaccination in dogs, Valle del Cauca, Colombia, 2009

Introduction. The province of Valle del Cauca has been free of dog rabies for more than 20 years. However, sylvatic rabies foci remain which are threats to the health of the populace and its pets. Rabies vaccination campaigns are carried out annually in all 42 counties of the province.

Objectives. The impact of dog vaccination was evaluated on the basis of humoral immunoresponse, population parameters and correlation with variables inherent to the vaccination process and logistics. Materials and methods. Sera and associated data were obtained from each of the 42 counties for a total sample of 569 rabies-vaccinated dogs. Rabies neutralizing antibodies were measured by quantitative ELISA. The data were analyzed with the statistical programs in Epi-Info 6.0.

Results. Nearly $10 \%$ of dogs were seronegative $(9.1 \%)$ and an additional $25.1 \%$ did not elicit an adequate humoral immune response to vaccination. Concentration of rabies neutralizing antibodies diminished gradually with the time after vaccination and was correlated with dog age and vaccine quality. No associations were noted between dog gender or breed.

Conclusions. These data permit the following recommendations: (1) only viable, non expired rabies vaccines must be used to immunize animals, (2) two doses of rabies vaccine must be applied during the first six months of dog life, (3) booster immunizations must be administered every year, (4) practices 
and processes related to rabies vaccination in private institutions must inspected regularly by health authorities.

Key words: rabies vaccines, rabies virus, Lyssavirus, zoonoses, epidemiological surveillance, immunity, Colombia.

La rabia es una zoonosis causada por virus neurotrópicos del género Lyssavirus, familia Rhabdoviridae, orden Mononegavirales $(1,2)$, que produce una encefalitis terminal, la cual afecta principalmente a animales y eventualmente a humanos expuestos a animales infectados. El virión rábico contiene $A R N$ no segmentado de cadena sencilla y sentido negativo, que codifica para las cinco proteínas estructurales del virus (3).

Cerca de 55.000 muertes humanas anuales ocurren por rabia, principalmente en los países en desarrollo de los continentes asiático, africano y americano, por orden de frecuencia $(4,5)$.

La transmisión de la rabia ocurre en dos formas epidemiológicas:

a) la urbana, con el perro como principal reservorio y transmisor, $y$

b) la silvestre, con animales como los murciélagos, zorros y lobos como reservorios y transmisores, y los gatos como transmisores.

La población colombiana se ha visto afectada históricamente por brotes urbanos y de origen silvestre (6-12). El brote urbano más reciente ocurrió en los años 2006-2008 en el Distrito Turístico de Santa Marta, departamento del Magdalena, el cual cobró la vida de cuatro humanos y de decenas de perros (10). Se necesitaron campañas intensivas de vacunación canina para lograr el control del brote, con un alto costo social y económico.

Brotes de rabia urbana de magnitudes similares al de Santa Marta, pueden ocurrir en otras ciudades capitales de departamento u otros centros urbanos de importancia en Colombia, si no se toman las precauciones necesarias, entre las que se cuentan programas anuales sostenidos de vacunación canina con coberturas superiores a 80 \%. En la mayoría de los departamentos de Colombia se llevan a cabo programas periódicos de vacunación

\footnotetext{
Correspondencia:

Andrés Páez, Laboratorio de Virología, Instituto Nacional de Salud, avenida-Calle 26 № 51-20, Bogotá, D.C., Colombia

Telefax: (571) 220 7700, extensión 1426

apaezm@ins.gov.co
}

Recibido: 27/10/11; aceptado:29/06/11 antirrábica en perros, aun sin reportarse casos de rabia en estos animales por décadas.

El departamento del Valle del Cauca tiene una población de 401.749 perros, según proyección del censo canino y felino del Valle del Cauca para el 2009 del Departamento Administrativo Nacional de Estadística (DANE). El número de perros vacunados contra la rabia en 2009 fue de 361.574, lo que corresponde a una cobertura promedio de vacunación de $90 \%$ en todos los municipios (Secretaría de Salud Valle del Cauca, 2009). La transmisión de la rabia en el ecosistema silvestre de este departamento ha representado una constante amenaza para perros y humanos $(7,13,14)$.

El presente estudio tuvo como objetivo investigar los porcentajes de perros con respuesta inmunitaria humoral adecuada a la vacunación, y los niveles de anticuerpos antirrábicos neutralizadores en perros vacunados durante el último año, en los municipios del departamento del Valle del Cauca, como una evaluación en campo a la vacunación antirrábica que se realiza en este departamento. El estudio representa una herramienta para las autoridades locales y nacionales de salud en la toma de decisiones sobre vacunación antirrábica canina, toda vez que los resultados y conclusiones que aquí se reportan pueden ser útiles y aplicados a los otros departamentos de Colombia y países en condiciones similares.

\section{Materiales y métodos}

\section{Muestra de estudio}

Se obtuvieron 569 sueros de igual número de perros que habían sido vacunados contra la rabia, de todos los municipios del departamento del Valle del Cauca. El criterio de inclusión fue el tener carné de vacunación antirrábica con fecha no mayor de un año al momento de la toma de muestra. Para la ubicación de los perros vacunados y sus domicilios, se utilizó la base de datos construida durante la vacunación antirrábica del departamento.

Cada municipio del departamento estuvo representado por un número de muestras igual a 0,3\% de su población canina vacunada, excepto los municipios más grandes del departamento (de más de 110.000 habitantes), tales como Cali, Buenaventura, Buga, Jamundí, Palmira, Tuluá 
y Yumbo que, por su gran número de perros, estuvieron representados por $0,1 \%$ de su población canina vacunada.

Al momento de la toma de suero, se hizo una encuesta a los propietarios para la captura de los datos de los perros, tales como municipio de residencia, sexo, edad, raza, estado general de salud, fecha de toma de muestra, fecha de vacunación, fecha de revacunación, entidad que realizó la vacunación y marca de la última vacuna antirrábica utilizada. Por confidencialidad, las marcas de las vacunas no se dan a conocer en este artículo; en su lugar, estas se identifican por los número del 1 al 17.

\section{Toma de las muestras de sangre, recolección $y$ almacenamiento del suero}

Se extrajeron 5 a $7 \mathrm{ml}$ de sangre en tubos vacutainer por punción de la vena radial del antebrazo o de la vena cefálica. Las muestras se dejaron coagular a temperatura ambiente y luego se centrifugaron por 15 minutos a $5.000 \mathrm{~g}$. Los sueros se separaron y se almacenaron congelados a $-20{ }^{\circ} \mathrm{C}$ hasta el momento de la medición del nivel de anticuerpos antirrábicos neutralizadores por el laboratorio.

\section{Titulación de anticuerpos antirrábicos neutralizadores en suero}

Se practicaron pruebas de Enzyme Linked Immunosorbent Assay (ELISA) cuantitativa para la detección y cuantificación de anticuerpos neutralizadores antiglucoproteina del virus rábico, en el suero de los perros (15-17). Para lo anterior, se utilizó el estuche Platelia Rabia ${ }^{\mathrm{TM}}$ (Bio-Rad), siguiendo la metodología y precauciones que recomienda el fabricante.

La prueba ELISA se fundamenta en la utilización de una fase sólida preparada con la glucoproteína extraída de la membrana del virus inactivado y purificado, siguiendo procedimientos descritos (18). También, se hace necesaria la utilización de un conjugado enzimático que corresponde a la proteína A de Staphylococcus aureus acoplado a peroxidasa, de acuerdo con protocolos ya descritos $(19,20)$.

En su última fase, la prueba se procesó en un lector de ELISA a $492 \mathrm{~nm}$. La comparación con una curva de calibración hecha con diferentes diluciones de un suero control con anticuerpos neutralizadores titulados en $\mathrm{UI} / \mathrm{ml}$, permite obtener los valores en los sueros problema. La prueba ELISA había sido validada previamente con pruebas de neutralización viral (21).

\section{Análisis de la información}

Se utilizaron los programas de computador Epi-Info 6.0 y Microsoft Excel® 2007, para el procesamiento y análisis estadístico de los datos.

\section{Resultados}

\section{Caracterización de los perros de la muestra}

Los datos de los perros del estudio se presentan en el cuadro 1 . El $47,6 \%$ eran machos y el $52,4 \%$, hembras. El 75,3\% eran de raza criolla, mientras que el 24,7\% restante se distribuyó en 23 razas, y las más representativas fueron labrador $(7,6 \%)$, pastor alemán (3,65 \%) y French poodle $(2,7 \%)$.

El $73,3 \%$ fue revacunado, mientras que $26,7 \%$ fue vacunado por primera vez. Se aplicaron 17 marcas de vacunas; sin embargo, las más utilizadas fueron Vac1, Vac2, Vac4 y Vac16, con frecuencias de $21,8 \%, 42,4 \%, 14,3 \%$ y $7,4 \%$, respectivamente. Las entidades vacunadoras fueron la Unidad de Saneamiento del Valle del Cauca $(49,7 \%)$, la Secretaría de Salud Departamental $(31,7 \%)$ y clínicas veterinarias privadas (18,6\%). La Unidad Ejecutora de Saneamiento del Valle fue la única entidad vacunadora en 32 de los 42 municipios del departamento, lo que representa una cobertura de $76,2 \%$.

\section{Concentraciones de anticuerpos neutralizadores}

El $9,1 \%$ de los perros resultaron seronegativos (concentración de anticuerpos antirrábicos neutralizadores=0). El $16 \%$ tuvo una concentración de anticuerpos neutralizadores entre 0,1 y $0,5 \mathrm{Ul} / \mathrm{ml}$, lo cual evidencia una respuesta inmunitaria humoral inadecuada; el $74,9 \%$ restante estuvo dentro del grupo de perros con respuesta inmunitaria humoral adecuada, es decir con concentraciones iguales 0 superiores a las $0,5 \mathrm{Ul} / \mathrm{ml}$. El promedio del título de anticuerpos neutralizadores fue de 2,43 Ul/ml; hubo 225 perros (39,5\%) en el intervalo de 0 a $1,0 \mathrm{UI} /$ $\mathrm{ml}, 99$ en el de 1,1 a 2,0 Ul/ml, 58 en el de 2,1 a $3,0 \mathrm{Ul} / \mathrm{ml}, 43$ en el 3,1 a $4,0 \mathrm{Ul} / \mathrm{ml}, 32$ en el 4,1 a $5,0 \mathrm{Ul} / \mathrm{ml}, 28$ en el de 5,1 a $6,0 \mathrm{Ul} / \mathrm{ml}, 10$ en el de 6,1 a $7,0 \mathrm{UI} / \mathrm{ml}$, y 8 en el de 7,1 a $8,0 \mathrm{UI} / \mathrm{ml}$. Hubo concentraciones mayores de $8,0 \mathrm{UI} / \mathrm{ml}$ en 37 perros. Los datos anteriores se presentan en la figura 1.

Al hacer idéntico análisis discriminando entre perros revacunados y sin revacunar, se obtienen datos casi idénticos entre estos dos grupos (figura 2).

Las hembras tuvieron en promedio $2,5 \mathrm{UI} / \mathrm{ml}$ de anticuerpos neutralizadores y los machos $2,4 \mathrm{UI} / \mathrm{ml}$. 


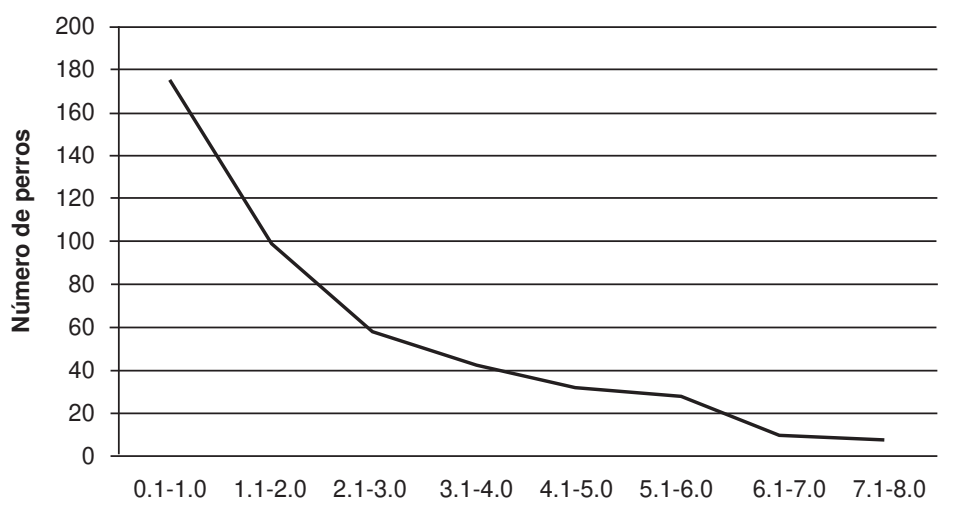

Concentración $\mathrm{UI} / \mathrm{ml}$

Figura 1. Correlación entre el número de perros y los intervalos de concentración de anticuerpos antirrábicos neutralizadores medidos en $\mathrm{UI} / \mathrm{ml}$. Diagrama que muestra la manera como disminuye el número de peros por intervalo de concentración de anticuerpos antirrábicos neutralizadores medidos en Ul/ml.

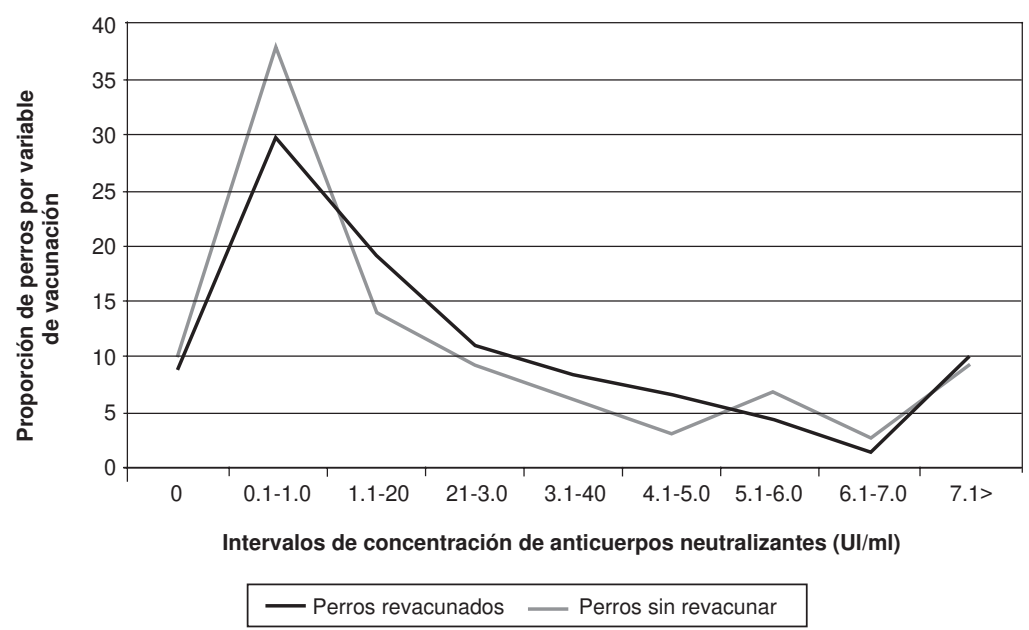

Figura 2. Correlación entre el número de perros por estado de vacunación y los intervalos de concentración de anticuerpos antirrábicos neutralizadores medidos en Ul/ml. Diagrama que muestra el porcentaje de perros por intervalo de concentración de anticuerpos neutralizadores $(\mathrm{Ul} / \mathrm{ml})$ en los grupos de perros revacunados y sin revacunar.

En las hembras, los porcentajes de seronegativas, de aquellas sin respuesta inmunitaria humoral adecuada, y de aquellas con respuesta adecuada, fueron $9,0 \%, 24,3 \%$ y $75,7 \%$, respectivamente; en los machos, dichos porcentajes fueron de 9,2 $\%, 26,1 \%$ y $73,9 \%$, respectivamente.

\section{Concentración de anticuerpos neutralizadores por municipio}

La concentración promedio de anticuerpos antirrábicos neutralizadores por municipio, osciló entre $0,5 \mathrm{Ul} / \mathrm{ml}$ (municipio de Ulloa) y 6,6 UI/ml (municipio de Argelia). Los municipios grandes (más de 110.000 habitantes), como Cali, Buenaventura, Cartago, Palmira y Tuluá, presentaron promedios intermedios de 2,81, 1,76, 2,11, 2,27 y 3,36 UI/ $\mathrm{ml}$, respectivamente. Los perros seronegativos estuvieron distribuidos en 13 de los 42 municipios del departamento, incluyendo a los municipios grandes: Buenaventura $(36,4 \%)$, Cali $(12,3 \%)$, Palmira $(11,1 \%)$ y Cartago $(10,7 \%)$. También, en los municipios grandes, llama la atención el alto porcentaje de perros sin respuesta inmunitaria humoral adecuada: Cali $(76,5 \%)$, Buenaventura $(59,1 \%)$, Sevilla $(58,3 \%)$, Buga $(33,3 \%)$ y Palmira $(25,9 \%)$ (cuadro 1).

\section{Seroconversión a la vacunación antirrábica según raza}

Los valores promedio de concentración de anticuerpos, y los porcentajes de seropositividad y de respuesta inmunitaria humoral adecuada 


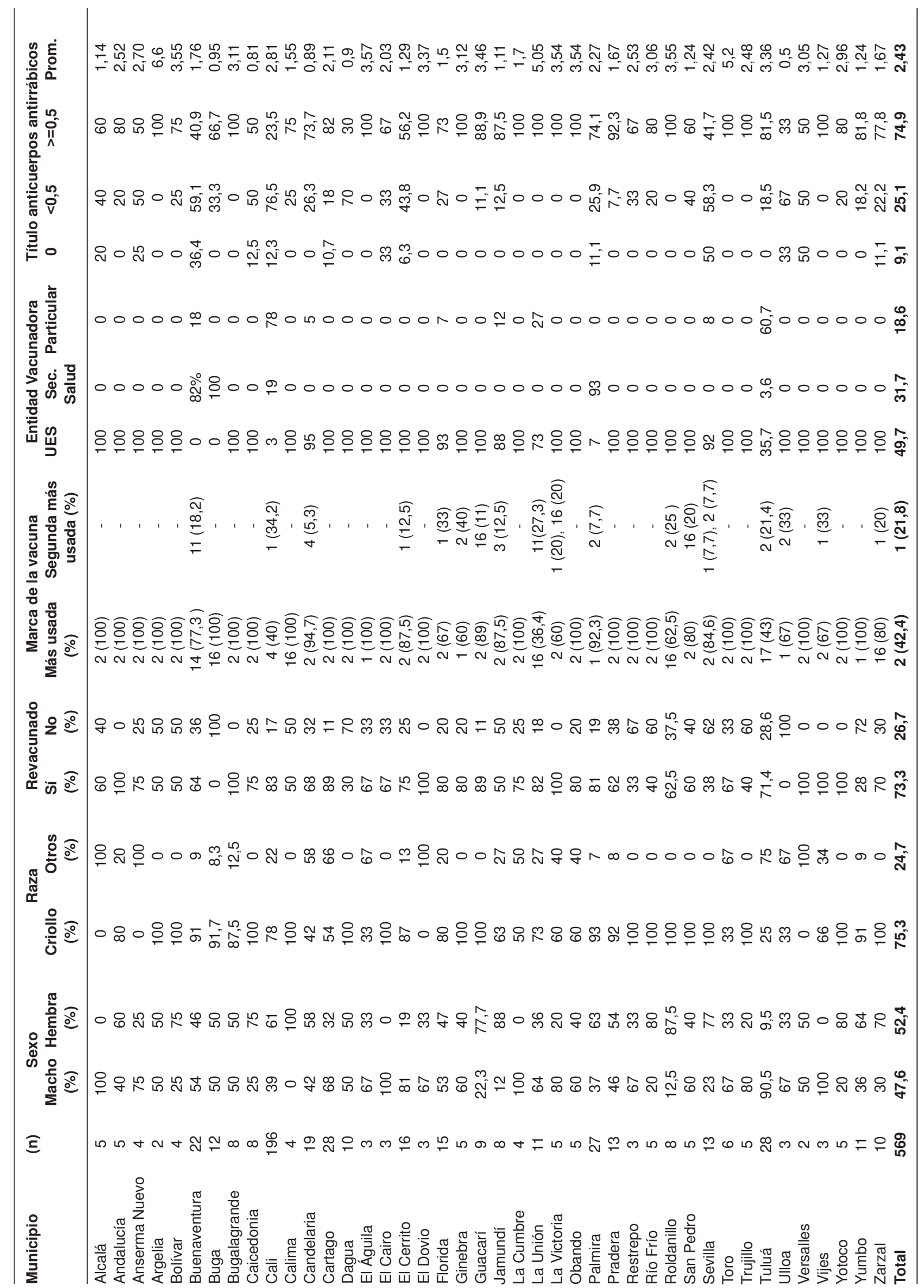


para las cuatro razas más representativas fueron, respectivamente, las siguientes: para perros criollos, 2,4 Ul/ml (89,6 \% y 73,3 \%); para labradores, 2,8 $\mathrm{UI} / \mathrm{ml}(97,6 \%$ y $85,4 \%)$; para pastores alemanes, 2,8 Ul/ml (89,5 \% y 73,7 \%), y finalmente, para French poodle, 2,1 Ul/ml (100\% y 93,3\%). No se encontraron diferencias estadísticamente significativas entre las cuatro razas anteriores.

\section{Perros seronegativos, sin respuesta inmunitaria humoral adecuada y con respuesta adecuada, por rango de edad}

El porcentaje de seronegativos disminuyó de $23,1 \%$, en perros menores de seis meses, a 2,1 $\%$, en aquellos entre tres y cuatro años de edad. Posteriormente, aumentó a 14,6\%, en edades entre cuatro y cinco años, y desapareció en las edades de cinco a siete años. Finalmente, en las edades de siete a ocho años, hubo 4,2\% de seronegativos.
El porcentaje de perros con respuesta inmunitaria humoral adecuada tuvo un sostenido incremento con la edad, de 53,9\%, en menores de seis meses, a $91,7 \%$ en los de ocho años. Únicamente los perros entre seis y siete años presentaron una caída con respecto al intervalo de edad inmediatamente anterior, llegando a 74 \% (figura 3).

\section{Seroconversión después de la última dosis de vacuna antirrábica}

En el grupo de perros revacunados, se observó una acentuada tendencia al descenso de la concentración de anticuerpos neutralizadores, con la amplitud del periodo de tiempo transcurrido entre la última dosis de vacuna y la toma de muestra. Así, el promedio de la concentración de anticuerpos neutralizadores cayó en los primeros dos meses desde la última dosis de vacuna, de 3,25 $\mathrm{Ul} / \mathrm{ml}$ en el primer mes a 2,8 $\mathrm{Ul} / \mathrm{ml}$ en el segundo

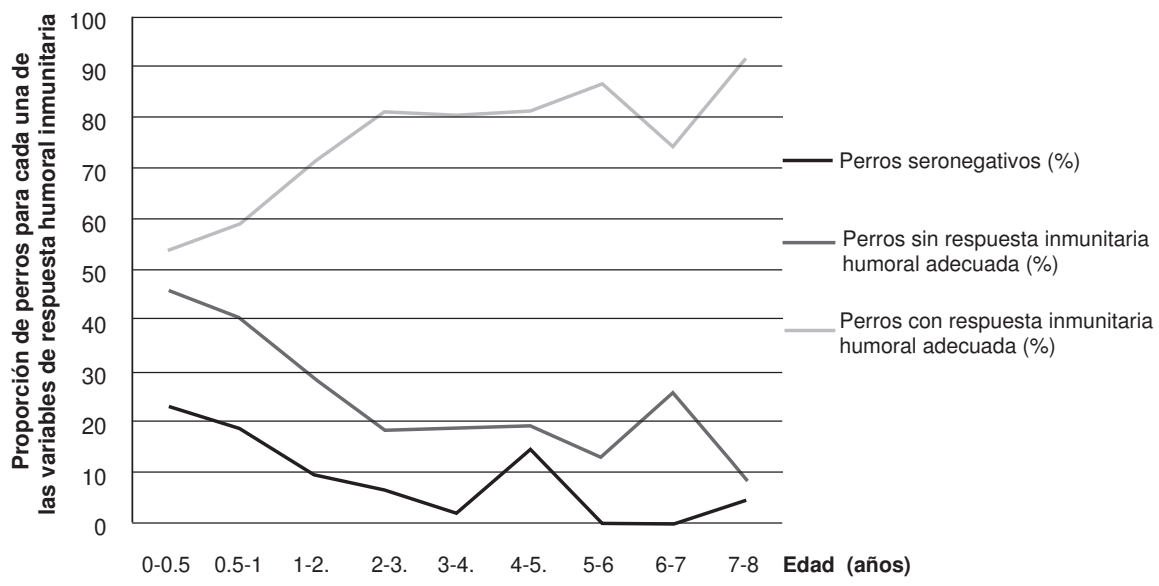

Figura 3. Tendencias de resultados seronegativos y de respuesta inmunitaria humoral, por edad. Gráfica que muestra las tendencias hacia la disminución de la proporción de perros seronegativos y sin respuesta inmunitaria humoral adecuada, y hacia el aumento de la proporción de perros con respuesta inmunitaria humoral adecuada, a medida que la edad aumenta.

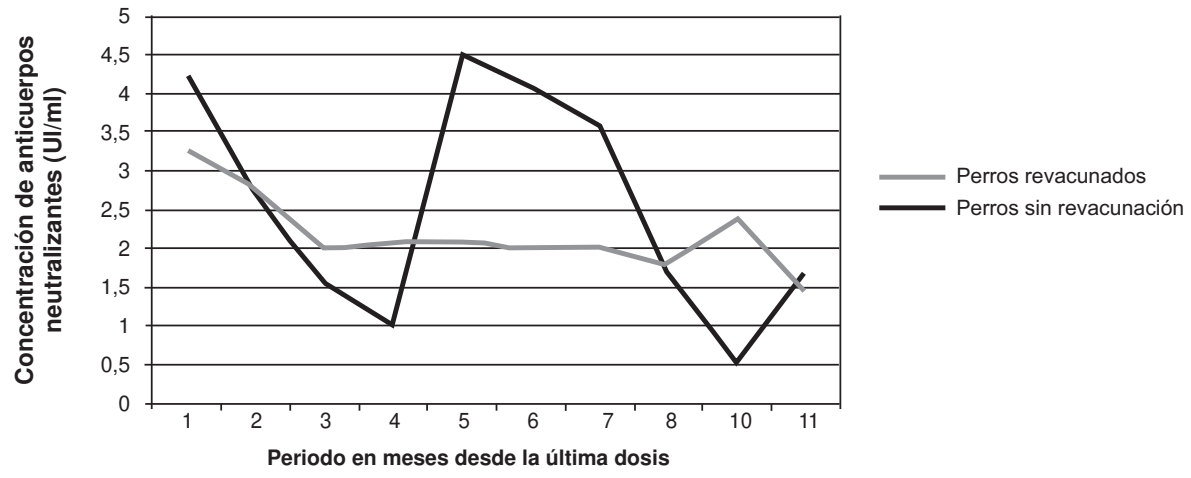

Figura 4. Tendencia de la concentración de anticuerpos antirrábicos neutralizadores en perros revacunados y sin revacunar, por tiempo desde la última dosis de vacuna antirrábica. Gráfica que muestra las tendencias de la concentración promedio de anticuerpos neutralizadores $(\mathrm{Ul} / \mathrm{ml}$ ) a medida que aumenta el periodo (meses) transcurrido desde la última dosis de vacuna antirrábica. 
mes, después del cual permaneció estable en aproximadamente 2,0 Ul/ml hasta el décimo mes, con un leve descenso a 1,45 $\mathrm{Ul} / \mathrm{ml}$ en el mes 11 (figura 4).

Por el contrario, en el grupo de perros sin revacunar, el promedio de la concentración de anticuerpos neutralizadores tuvo un comportamiento impredecible después de la única dosis de vacuna, sin mostrar una tendencia definida, la cual inicialmente presentó un descenso en los primeros cuatro meses, pasando de 4,25 Ul/ml a 1,0 Ul/ml. A partir del quinto mes, se incrementó a 4,5 Ul/ml y continuó descendiendo paulatinamente hasta el décimo, con 0,5 Ul/ml (figura 4).

\section{Seroconversión por entidad vacunadora}

La Unidad Ejecutora de Saneamiento del Valle vacunó 276 perros en 39 municipios, mientras que la Secretaría de Salud Departamental y las entidades particulares vacunaron 103 y 176 perros en 6 y 8 municipios, respectivamente. Las variables medidas en los tres grupos, fueron: promedio de títulos de anticuerpos neutralizadores, porcentaje de perros seropositivos y porcentaje de perros con respuesta inmunitaria humoral adecuada, cuyos respectivos valores fueron: Unidad Ejecutora de Saneamiento del Valle, 2,3 Ul/ml, 76,3 \% y 93,4 $\%$; entidades particulares, 2,7 UI/ml, 71,5 \% y 86,6 $\%$; y Secretaría de Salud Departamental, 2,5 Ul/ml, $76,7 \%$ y $91,3 \%$.

\section{Seroconversión según las diferentes marcas de vacuna antirrábica}

Para la última dosis se utilizaron vacunas antirrábicas de 17 diferentes marcas; sin embargo, sólo se analizaron perros vacunados con ocho de ellas, por su significativo número de perros (once o más), las cuales produjeron concentraciones promedio de anticuerpos neutralizadores superiores a $1,9 \mathrm{Ul} / \mathrm{ml}$ y porcentajes de perros con respuesta inmunitaria humoral adecuada superiores a 64,5 $\%$, valores que se ubican dentro de lo esperado.

No obstante, la vacuna Vac14 produjo únicamente 0,9 Ul/ml de concentración promedio de anticuerpos neutralizadores, 70,6 \% de perros sin respuesta inmunitaria humoral adecuada y 47,1\% de perros seronegativos, lo cual demuestra su baja efectividad (figura 5).

\section{Discusión}

\section{Seroconversión por municipio en el Valle del Cauca}

Los perros sin respuesta inmunitaria humoral adecuada fueron 144 (25,1\%). El de estos 144 perros, $96(64,1 \%)$ se concentraron en seis municipios (Cali, Buenaventura, Sevilla, Dagua, El Cerrito y Palmira). De hecho, en esos municipios, $33,85 \%$ de los perros no demostraron respuesta inmunitaria humoral adecuada, en contraste con $16,8 \%$ en el resto de los municipios.

Los datos son aún más contundentes cuando se investiga la manera como se distribuyeron los resultados seronegativos. En el estudio, hubo 50 perros seronegativos (9,1\%), $74 \%$ de los cuales estaban concentrados en sólo tres municipios (Cali, Buenaventura y Sevilla); por lo tanto, en estos tres municipios hubo $16,0 \%$ de perros seronegativos, mientras que en el resto de municipios hubo 3,85 \%.

El caso más grave fue el de Cali, donde se concentró $46 \%$ del total de seronegativos y $36 \%$ del total sin respuesta inmunitaria humoral adecuada. Llama la atención que, en Cali, el $78 \%$ de las últimas dosis de vacuna fueron aplicadas por entidades particulares; de hecho, el $100 \%$ de los seronegativos y el 77,8 $\%$ de los perros sin respuesta inmunitaria humoral adecuada, fueron inmunizados en entidades particulares. Además, Cali fue el municipio con

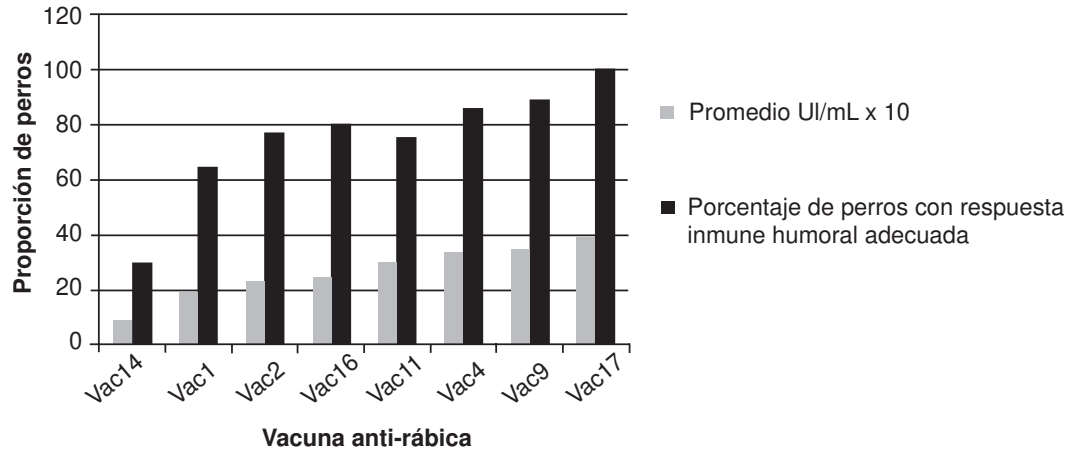

Figura 5. Seroconversión inducida por ocho marcas de vacuna antirrábica. Diagrama que muestra la eficacia de las ocho vacunas más utilizadas en el presente estudio, medida en el porcentaje de perros con respuesta inmunitaria humoral adecuada a la vacunación y en el grado de seroconversión de anticuerpos neutralizadores. 
mayor participación de entidades particulares en vacunación antirrábica. Sin tener en cuenta a Cali, las entidades particulares vacunaron únicamente 28 perros en siete municipios.

\section{Seroconversión asociada con edad, pero no con raza ni sexo}

Al seleccionar las cuatro razas predominantes, y comparar los valores de seroconversión y porcentaje de perros con respuesta inmunitaria humoral adecuada, se observaron ligeras diferencias que carecen de significancia estadística y podrían atribuirse, no exclusivamente a la raza, sino a múltiples factores, como tipo de vacuna utilizada, edad de los individuos, estado de revacunación, periodo entre refuerzo y toma de muestra, etc. Igualmente, no se encontraron diferencias significativas por sexo.

Por lo contrario, con la edad se observó una tendencia bien definida en resultados seropositivos, concentración de anticuerpos neutralizadores y porcentaje de perros con respuesta inmunitaria humoral adecuada, lo que concuerda con estudios anteriores (22-26). Los perros con mayor edad habían sido inmunizados más veces que los jóvenes, lo que explicaría esta tendencia e indicaría, además, que los perros en el departamento del Valle del Cauca han estado sujetos periódicamente a vacunación antirrábica. El resultado seronegativo y la falta de respuesta inmunitaria humoral adecuada en menores de un año, fueron superiores a $20 \%$ y $43 \%$, respectivamente, constituyéndose en grupo de riesgo para la infección y transmisión de la rabia en ecosistemas urbanos. Esto indica que la primovacunación antirrábica tuvo una eficacia de $60 \%$ y que los refuerzos posteriores incrementaron a casi $92 \%$ la proporción de perros con respuesta inmunitaria humoral adecuada, al mismo tiempo que disminuyeron a $0 \%$ los resultados negativos en edades de cinco a sieta años, y a 4,2\%, en edades de siete a ocho años. Con el fin de disminuir el riesgo en cachorros, sería necesario aplicar como mínimo dos refuerzos en el primer año de vida, como se ha propuesto en anteriores estudios (25).

\section{Disminución de la concentración de anticuerpos neutralizadores después del refuerzo}

De acuerdo con estudios anteriores $(22,23,24,26)$, se observó una disminución en la concentración de anticuerpos neutralizadores, desde 3,4 UI/ $\mathrm{ml}$ en el primer mes hasta $1,5 \mathrm{UI} / \mathrm{ml}$ en el cuarto mes, después del último refuerzo, con leves incrementos del quinto al séptimo mes.
Sin embargo, los resultados seropositivos y la respuesta inmunitaria humoral adecuada no mostraron una tendencia definida, mostrándose ligeramente variables después del último refuerzo, con oscilaciones entre $89,5 \%$ y $100 \%$, y $73,3 \%$ y $93,3 \%$, respectivamente. Sin embargo, ambos valores presentaron una disminución notable a partir del mes 12, de tal manera que únicamente 68 $\%$ y $52 \%$, respectivamente, mostraron resultado seropositivo y respuesta inmunitaria humoral adecuada. Lo anterior demuestra la necesidad de que la vacunación sea anual.

\section{Seroconversión en la muestra de estudio}

Las concentraciones de los anticuerpos neutralizadores se distribuyeron en el rango de 0,1 a 8,0 $\mathrm{UI} / \mathrm{ml}$ (figura 1). Para este análisis, se excluyeron los perros con concentraciones superiores, debido a que en ellos el valor exacto de la concentración no se investigó. Igualmente, se excluyeron los seronegativos, por considerarse que en muchos casos esta condición resulta anormal.

El rango de concentración con el mayor número (175) de perros fue de 0,1 a 1,0 Ul/ml; posteriormente, los rangos presentaron cada vez menos animales, de tal manera que entre 1,1 y $2,0 \mathrm{UI} / \mathrm{ml}$, hubo 99 perros, entre 2,1 y $3,0 \mathrm{UI} / \mathrm{ml}$ hubo 58 , entre 3,1 y $4,0 \mathrm{UI} / \mathrm{ml}$ hubo 43 , entre 4,1 y $5,0 \mathrm{UI} / \mathrm{ml}$ hubo 32 , entre 5,1 y $6,0 \mathrm{UI} / \mathrm{ml}$ hubo 28 , entre 6,1 y $7,0 \mathrm{UI} / \mathrm{ml}$ hubo 10 , y entre 7,1 y $8,0 \mathrm{UI} / \mathrm{ml}$ hubo 8 . Del total de la muestra, 37 perros tuvieron concentraciones mayores de $8,0 \mathrm{Ul} / \mathrm{ml}$ y $225(39,5 \%)$ estuvieron entre 0 y $1,0 \mathrm{Ul} / \mathrm{ml}$, siendo éste el intervalo con mayor número de perros. De este grupo, sin embargo, 50 fueron seronegativos.

\section{Seroconversión según raza}

Al seleccionar las cuatro razas predominantes y comparar los valores de seroconversión a la vacuna antirrábica, se observaron ligeras diferencias que podrían atribuirse, no necesariamente a raza, sino a factores como tipo de vacuna utilizada, edad de los individuos, estado de revacunación, periodo entre refuerzo y toma de muestra, etc.

\section{Seroconversión según marca de la vacuna antirrábica}

De las ocho vacunas analizadas, siete produjeron concentraciones promedio de anticuerpos neutralizadores superiores a $1,9 \mathrm{Ul} / \mathrm{ml}$ y porcentaje de perros con respuesta inmunitaria humoral adecuada superior a $64,5 \%$, valores que se ubicaron dentro de los rangos aceptables. 
A este respecto, es de resaltar la gran efectividad de las vacunas 4,9 y 17, las cuales produjeron concentraciones promedio de anticuerpos neutralizadores de $3,4 \mathrm{UI} / \mathrm{ml}, 3,5 \mathrm{UI} / \mathrm{ml}$ y $3,9 \mathrm{UI} /$ $\mathrm{ml}$, y porcentajes de perros con respuesta inmunitaria humoral adecuada, de 85,7, 88,9 y 100 , respectivamente. Estas tres vacunas fueron aplicadas por entidades particulares en 3, 2 y 1 municipios, respectivamente.

Una de las vacunas analizadas produjo 0,9 UI/ $\mathrm{ml}$ de concentración promedio de anticuerpos neutralizadores y $29,4 \%$ de perros protegidos, lo cual demostró su escasa efectividad. Dicha vacuna fue aplicada por la Secretaría de Salud Departamental en el municipio de Buenaventura, a 17 perros criollos revacunados y no revacunados, de edades entre seis meses y 11 años. El periodo entre la aplicación de esta vacuna y la toma de la muestra, estuvo entre los dos y los 22 meses. Se puede, entonces, inferir que la poca efectividad de esta vacuna se relaciona estrechamente con factores inherentes a la producción, manejo o la calidad, tales como lote de fabricación, cadena de frío o fecha de vencimiento.

Con el fin de obtener análisis más reales y sustraer de la muestra de estudio a los perros vacunados con la vacuna 14, se modificaron algunos valores más que otros. Entre los valores que más se modificaron están los datos de seroconversión y porcentaje de perros con respuesta inmunitaria humoral adecuada en el municipio de Buenaventura $y$, esas mismas variables, para la Secretaría de Salud Departamental.

Por lo anterior y bajo el nuevo análisis, los perros seronegativos en Buenaventura pasan de $36,4 \%$ a $0 \%$. Igualmente, los perros sin respuesta inmunitaria humoral adecuada en este municipio, pasaron de $59,1 \%$ a $20 \%$. Asimismo, los indicadores de vacunación de la Secretaría de Salud Departamental mejoraron al disminuir los resultados seronegativos de $8,73 \%$ a $1,2 \%$, y la respuesta inmunitaria humoral inadecuada de $23,3 \%$ a $14 \%$.

Igualmente, bajo el nuevo análisis, los perros seronegativos en la muestra pasaron de 50 a 42, lo que los hizo bajar de $9,1 \%$ al 7,9\%. El $69 \%$ de estos animales quedó concentrado en sólo dos de los 42 municipios del departamento (Cali y Sevilla).

Causas de seronegativos y de falta de respuesta inmunitaria humoral adecuada

Los perros sin respuesta inmunitaria humoral adecuada fueron 144 (25,1\%), entre los cuales
50 fueron seronegativos $(9,1 \%$ del total). Existen varias posibles razones para esto, a saber:

1) Aplicación de vacunas antirrábicas de baja potencia. De los 17 perros que recibieron la vacuna número $14,12(70,5 \%)$ no presentaron respuesta inmunitaria humoral adecuada y, aun más, 8 (47\%) de estos 12 perros fueron seronegativos, lo que indica dicha vacuna no cumplía con uno o varios de los criterios de calidad al momento de su aplicación, como los inherentes al proceso de manufactura, el adecuado mantenimiento de la cadena de frío, la aplicación posterior a la fecha de expiración o el deficiente cálculo de esta fecha.

2) Falta de aplicación anual del refuerzo. De los 25 perros que no recibieron al término de un año después de la última dosis, 12 no produjeron respuesta inmunitaria humoral adecuada. Dentro de este grupo, 8 fueron seronegativos.

3) Edad de los perros. De los 57 menores de un año, 25 (43,9 \%) no produjeron una respuesta inmunitaria humoral adecuada y, de ellos, 11 $(19,3 \%)$ fueron seronegativos.

4) Deficiente aplicación de la vacuna. De los 176 perros vacunados por particulares, 49 (28\%) no produjeron una respuesta inmunitaria humoral adecuada y, entre ellos, 23 (13\%) resultaron seronegativos. Visto de otra manera, $46 \%$ de los seronegativos y $34 \%$ de los que no produjeron respuesta inmunitaria humoral adecuada, fueron inmunizados en entidades particulares, siendo el primer porcentaje muy significativo.

En conclusión, con los cuatro factores anteriormente mencionados se explica que 76 perros no hayan producido respuesta inmunitaria humoral adecuada a la vacunación y que, dentro de este grupo, 35 perros fueran seronegativos. Es decir que con estos cuatro factores, se explica el $48 \%$ de ausencia de respuesta inmunitaria humoral adecuada y el $70 \%$ de resultados seronegativos de toda la muestra analizada en este estudio. Los factores relacionados con la capacidad, las limitaciones y los mecanismos biológicos de inmunidad propios de cada perro, no se analizaron en este estudio.

Con la finalidad de aumentar los resultados seropositivos, así como las concentraciones de anticuerpos neutralizadores y la respuesta inmunitaria humoral adecuada a la vacunación antirrábica, se deben aplicar con criterios estrictos 
de calidad de fabricación, con conservación de la cadena de frío y antes de su fecha de expiración.

Las entidades particulares deben tener personal idóneo para aplicar la vacuna antirrábica, así como la capacidad adecuada de almacenamiento y frecuente recambio de las dosis.

Los periodos entre los refuerzos de la vacuna antirrábica no deben ser superiores a 12 meses. La primovacunación debe constar de más de una dosis, con el fin de disminuir los resultados seronegativos y la falta de respuesta inmunitaria humoral adecuada, durante su primer año de vida.

Para lo anterior, se deben hacer investigaciones sobre la inmunidad humoral adquirida con dos y más dosis de vacuna antirrábica, y el lapso de tiempo más conveniente entre ellas.

\section{Agradecimientos}

Este estudio fue realizado con fondos económicos de la Secretaría Departamental de Salud del Valle del Cauca de Cali, la Unidad Ejecutora de Saneamiento del Valle del Cauca de Cali y el Instituto Nacional de Salud. Los autores agradecen a todos los funcionarios de las citadas entidades, y a los del Centro de Zoonosis de Cali, involucrados en este estudio, sin cuya colaboración hubiese sido imposible su realización.

\section{Conflicto de intereses}

Los autores del artículo hacen constar que no existe, de manera directa o indirecta, ningún tipo de conflicto de intereses financieros, académicos o personales, que puedan poner en peligro la validez de la investigación.

\section{Financiación}

Los recursos económicos necesarios para el trabajo de campo y de laboratorio fueron aportados por la Secretaría Departamental de Salud del Valle del Cauca, la Unidad Ejecutora de Saneamiento del Valle del Cauca y el Instituto Nacional de Salud de Colombia.

\section{Referencias}

1. Koprowski H. The mouse inoculation test. In: Meslin FX, Kaplan MM, Koprowski H, editors. Laboratory techniques in rabies. Fourth edition. Geneva: World Health Organization; 1996. p. 80-7.

2. Dean DJ, Abelseth MK, Atanasiu P. The florescent antibody test. In: Meslin FX, Kaaplan MM, Koprowski H, editors. Laboratory techniques in rabies. Fourth edition. Geneva: World Health Organization; 1996. p. 88-95.
3 Wunner WH, Larson JK, Dietzchold B, Smith CL. The molecular biology of rabies virus. Rev infect Dis. 1988;10:771-84

4. Knobel DL, Cleaveland S, Coleman PG, Fevre EM, Meltzer MI, Miranda ME, et al. Re-evaluating the burden of rabies in Africa and Asia. Bull World Health Organ. 2005;83:360-8.

5. Warrell MJ. Emerging aspects of rabies infection: With a special emphasis on children. Curr Opin Infect Dis. 2008;21:251-7.

6. Páez A, Saad C, Núñez C, Boshell J. Molecular epidemiology of rabies in northern Colombia 1994-2003: Evidence for human and fox rabies associated with dogs. Epidemiol Infect. 2005;133:529-36.

7. Páez A, Núñez C, García C, Boshell J. Molecular epidemiology of rabies epizootics in Colombia: Evidence for human and dog rabies associated with bats. J Gen Virol. 2003;84:795-802.

8. Páez A, Núñez C, García C, Boshell J. Epidemiología molecular de epizootias de rabia en Colombia 1994-2002. Evidencia de rabia humana y canina asociada a quirópteros. Biomédica. 2003;23:19-30.

9. Hughes GJ, Páez A, Boshell J, Rupprecht CE. A phylogenetic reconstruction of the epidemiological history of canine rabies virus variants in Colombia. Infect Gen Evol. 2004;4:45-51.

10. Páez A, Rey G, Agudelo C, Dulce A, Parra E, DíazGranados $\mathrm{H}$, et al. Brote de rabia urbana transmitida por perros en el Distrito de Santa Marta, Colombia, 2006-2008. Biomédica. 2009;29:424-36.

11. Valderrama J, García I, Figueroa G, Rico E, Sanabria $\mathbf{J}$, Rocha N, et al. Brotes de rabia humana transmitida por vampiros en los municipios de Bajo y Alto Baudó, departamento del Chocó, Colombia 2004-2005. Biomédica. 2006;26:387-96

12. Páez A, Polo L, Heredia D, Núñez C, Rodríguez $\mathbf{M}$, Agudelo C, et al. Brote de rabia humana transmitida por gato en el municipio de Santander de Quilichao, Colombia, 2008. Rev Salud Pública. 2009;11:931-43.

13. Otero JA, Arango S, Restrepo MA, Alberico H, Gutiérrez $\mathbf{M}$, Márquez $\mathbf{A}$, et al. Prevalencia del virus rábico en quirópteros del área municipal de Cali, Colombia. Colombia Médica. 1993,24:137-41.

14. Núñez CL, Aldaz JJ, Escobar H, Cuadros ME. Primer hallazgo de virus rabia silvestre en el murciélago insectívoro Eptesicus brasiliensis en Cali, Colombia. Revista de la Asociación Colombiana de Ciencias Biológicas. 2001;12:5761.

15. Engvall E, Perlmann P. Enzyme-linked immunosorbent assay (ELISA). Quantitative assay of immunoglobulin G. Immunochemistry. 1971;8:871-4.

16. Atanasiu P, Savy V, Gibert C. Rapid immunoenzymatic technique for titration of rabies antibodies IgG and IgM results. Med Microbiol Immunol. 1978;166:201-8.

17. Atanasiu P, Perrin P, Delagneau JF. Use of an enzyme immunoassay with protein $A$ for rabies antigen and antibody determination. Dev Biol Stand. 1980;46:207-15.

18. Perrin P, Versmisse P, Delagneau JF, Lucas G, Rollin PE, Sureau P. The influence of the type of immunosorbent 
on rabies antibody EIA: Advantages of purified glycoprotein over whole virus. J Biol Stand. 1986;14:95-102.

19. Forsgren A, Sjoquist J. "Protein A" from S. aureus. I. Pseudo-immune reaction with human gamma globulin. $J$ Immunol. 1966;97:822-7.

20. Biderfield P, Ghetie V, Sjoquist J. Demonstration and assaying of IgG antibodies in tissues and on cells by labelled staphylococcal protein A. J Immunol Methods. 1975;6:24959.

21. Feyssaguet M, Dacheux L, Audry L, Compoint A, Morize JL, Blanchard I, et al. Multicenter comparative study of a new ELISA, PLATELIA RABIES II, for the detection and titration of antirabies glycoprotein antibodies and comparison with the rapid fluorescent focus inhibition test (RFFIT) on human samples from vaccinated and nonvaccinated people. Vaccine. 2007;25:2244-51.

22. Cliquet F, Verdier Y, Sagné L, Aubert M, Schereffer JL, Selve M, et al. Neutralizing antibody titration in 25,000 sera of dogs and cats vaccinated against rabies in France, in the framework of the new regulations that offer an alternative to quarantine. Rev Sci Tech. 2003;22:857-66.

23. Mansfield KL, Burr PD, Snodgrass DR, Sayers R, Fooks AR. Factors affecting the serological response of dogs and cats to rabies vaccination. Vet Rec. 2004;154:423-6.

24. Kennedy LJ, Lunt M, Barnes A, McElhinney L, Fooks AR, Baxter DN, et al. Factors influencing the antibody response of dogs vaccinated against rabies. Vaccine. 2007;25:8500-7.

25. Jakel V, König M, Cussler K, Hanschmann K, Thiel HJ. Factors influencing the antibody response to vaccination against rabies. Dev Biol (Basel). 2008;131:431-7.

26. Hampson K, Dushoff J, Cleaveland S, Haydon DT, Kaare M, Packer C, et al. Transmission dynamics and prospects for the elimination of canine rabies. PLoS Biol. 2009;7:e53. 